\title{
APPENDIX \\ V. HYDROCARBON AND KEROGEN STUDIES ON RED SEA AND GULF OF ADEN CORES
}

\author{
John M. Hunt, Department of Chemistry, Woods Hole Oceanographic Institution, Woods Hole, Massachusetts
}

\begin{abstract}
Light hydrocarbons in the $\mathrm{C}_{4}-\mathrm{C}_{7}$ range have been found in quantities ranging from 49 to 121 parts per billion (ppb) in one Red Sea core and five Gulf of Aden cores of Pleistocene-late Miocene age. It appears that these hydrocarbons are forming in situ from the decomposition of organic matter. Heavy hydrocarbons in the $\mathrm{C}_{15}+$ range were found in concentrations ranging from 34 to $134 \mathrm{ppm}$ in three cores analyzed. These hydrocarbons are largely naphtenic with CPIs of the paraffin fraction ranging from 1.5 to 2.5 .
\end{abstract}

\section{RESULTS AND DISCUSSION}

A Red Sea core from Leg 23 and two Gulf of Aden cores from Leg 24 were analyzed in detail for both light and heavy hydrocarbons. In addition, three other Gulf of Aden cores were analyzed for the light hydrocarbons. The methods of analysis were previously reported in the Leg 22 Initial Reports.

Data on the distribution of light hydrocarbons are shown in Table 1. Twenty-four alkanes, isoalkanes, and cycloalkanes (naphthenes) in the $\mathrm{C}_{4}$ to $\mathrm{C}_{7}$ range were identified in amounts ranging from 49 to $121 \mathrm{ppb}$ in these samples. In addition, benzene and toluene were present in all samples in amounts ranging up to $50 \mathrm{ppb}$. However, they are not reported because of problems in benzene contamination.

The hydrocarbons shown in Table 1 are not found in living organisms. Consequently, their presence can only be explained by in situ formation from the organic matter or seepage from deeper horizons. Since the yield of $\mathrm{C}_{4}$ to $\mathrm{C}_{7}$ hydrocarbons and of total $\mathrm{C}_{15}+$ hydrocarbons relative to the total organic carbon is low compared to areas of clearly defined seeps, it is unlikely that these results are due to seepage. Rather, it appears that some diagenetic chemical alterations have occurred to produce both the trace hydrocarbons in the $\mathrm{C}_{4}$ to $\mathrm{C}_{7}$ range and the distributions noted in the $\mathrm{C}_{15}+$ range. For example, the distribution of $\mathrm{C}_{4}$ to $\mathrm{C}_{7}$ hydrocarbons in Table 1 is much more erratic than would occur from a petroleum seep. Sample 232A-1-6 shows about 80 percent of its total hydrocarbons to be composed of $n$-butane and isopentane. Sample 233A-7-4 has $n$-pentane representing about 40 percent of its total $\mathrm{C}_{4}$ to $\mathrm{C}_{7}$ hydrocarbons. These high yields of a few hydrocarbons are typical of early diagenesis in which the nature of the organic matter determines the type of hydrocarbons broken off. In the last sample mentioned there was probably an unusual proportion of $n$-pentane side chains in the organic matrix.

Table 2 contains analytical data for the extractable $\mathrm{C}_{15+}$ fraction from one Red Sea and two Gulf of Aden cores. The total $\mathrm{C}_{15}+$ saturate and aromatic hydrocarbons in the extractable bitumen ranges from 4 to 6 percent. This is typical of young, immature organic matter containing the hydrocarbons formed by living organisms, plus a few diagenetically formed hydrocarbons. It is not typical of seeps which would have at least $25 \%$ hydrocarbons in the extractable bitumen.

The saturate hydrocarbon analysis shows an unusually high, 74 to 85 percent naphthene content, considering that naphthenes have not been identified as major constituents of living marine organisms. Recent studies at W.H.O.I. indicate that some of these naphthenes may be formed by microorganisms in sea-floor sediments.

The correlation preference index (CPI), which is the ratio of odd to even normal paraffins, is in the range one would expect from a mixture of hydrocarbons derived from marine sources and those from land sources. The kerogen of these three samples was examined microscopically and found to contain mixtures of herbaceous, woody, and amorphous material. The Red Sea sample (119A-13-5) was reported to contain large quantities of spore materials and the most herbaceous and woody material of all three samples. This explains the CPI value of 2.5 for the Red Sea sample since higher CPI values result from land-derived material. The lower values for the Gulf of Aden samples are typical of the amorphous marine organic matter which was dominant in the visual examination of these samples. All three samples were defined as immature, that is, the kerogen showed no appreciable alteration due to thermal effects. The pristane/phytane ratios indicate that some early diagenesis has occurred since phytane is not found in living marine organisms.

Figure 1 shows the gas chromatograph tracings of the saturate hydrocarbons for the Red Sea core and Sample 232A-1-6 from the Gulf of Aden. The large area under the curve to the baseline consists of an undefined mixture of naphthenes and isoparaffins. The bimodality observed in this mixture for the Gulf of Aden core has been seen in a number of deep-sea core analyses, but its origin is as yet unknown.

In summary, the Red Sea organic matter is predominantly land derived, with minor amounts of amorphous marine material, whereas the Gulf of Aden kerogen is predominantly marine with minor amounts of terrestrial organic matter. The heavy hydrocarbons appear to be 
TABLE 1

Light Hydrocarbon Yields from Red Sea and Gulf of Aden Cores

\begin{tabular}{|c|c|c|c|c|c|c|}
\hline \multirow[b]{2}{*}{$\mathrm{C}_{4}-\mathrm{C}_{7}$ Hydrocarbons ${ }^{\mathrm{a}}$} & \multicolumn{6}{|c|}{ Sample Yields (in ppb by weight) } \\
\hline & $229 A-13-5$ & $232 A-1-6$ & $232 \mathrm{~A}-15-2$ & $233-19-5$ & $233 \mathrm{~A}-1-3$ & $233 \mathrm{~A}-7-4$ \\
\hline Isobutane & 2.1 & 1.0 & 0.5 & 0.4 & 0.4 & 2.5 \\
\hline$n$-Butane & 1.8 & 59.8 & 1.7 & 2.4 & 2.4 & 1.2 \\
\hline Isopentane & 2.2 & 41.6 & 5.6 & 3.3 & 4.9 & 1.3 \\
\hline$n$-Pentane & 3.3 & 2.3 & 2.9 & 2.6 & 4.7 & 45.8 \\
\hline 2, 2-Dimethylbutane & 0.6 & 0.2 & 0.3 & 0.4 & 0.3 & 0.5 \\
\hline Cyclopentane & 0.8 & 0.6 & 0.3 & 1.9 & 0.9 & 3.3 \\
\hline 2, 3-Dimethylbutane & 0.8 & 0.3 & 0 & 0.9 & 0 & 0 \\
\hline 2-Methylpentane & 2.1 & 3.6 & 1.7 & 2.2 & 3.5 & 3.0 \\
\hline 3-Methylpentane & 1.6 & 0.6 & 1.2 & 1.5 & 2.5 & 1.8 \\
\hline$n$-Hexane & 2.5 & 1.4 & 0.9 & 6.1 & 2.0 & 6.9 \\
\hline Methylcyclopentane & 3.0 & 2.0 & 1.6 & 2.2 & 1.8 & 2.6 \\
\hline Cyclohexane & 2.2 & 0.4 & 0.8 & 4.0 & 0.9 & 3.0 \\
\hline 3, 3-Dimethylpentane & 0.9 & 0 & 1.1 & 1.3 & 0.3 & 0.6 \\
\hline 1, 1-Dimethylcyclopentane & 0.8 & 0 & 0.8 & 0.9 & 0.3 & 0.6 \\
\hline 2-Methylhexane & 3.2 & 0.5 & 9.6 & 6.4 & 1.3 & 3.6 \\
\hline 2, 3-Dimethylpentane & 1.8 & 0.6 & 0 & 0 & 0 & 0 \\
\hline 1, cis-3-Dimethylcyclopentane & 3.1 & 0 & 0 & 0 & 0 & 0 \\
\hline 3-Methylhexane & 3.9 & 1.5 & 7.0 & 7.5 & 1.6 & 5.7 \\
\hline 1 trans-3-Dimethylcyclopentane & 0.2 & 1.0 & 4.8 & 0 & 0.9 & 0 \\
\hline 1t-2-Dimethylcyclopentane & 0.7 & 0.5 & 1.9 & 3.1 & 1.4 & 4.8 \\
\hline 3-Ethylpentane & 0.3 & 0 & 0 & 0 & 0 & 0 \\
\hline$n$-Heptane & 3.6 & 1.8 & 3.5 & 9.1 & 1.8 & 9.8 \\
\hline 1, c-2-Dimethylcyclopentane & 0.9 & 0.2 & 2.0 & 0.8 & 0.5 & 1.1 \\
\hline Methylcyclohexane & 7.0 & 1.7 & 8.1 & 12.1 & 2.7 & 10.5 \\
\hline Totals & 49.4 & 121.6 & 56.3 & 69.1 & 35.1 & 108.6 \\
\hline
\end{tabular}

aBenzene and toluene were present in all samples, but are not reported because of possible contamination.

TABLE 2

Analytical Data on Red Sea and Gulf of Aden Cores

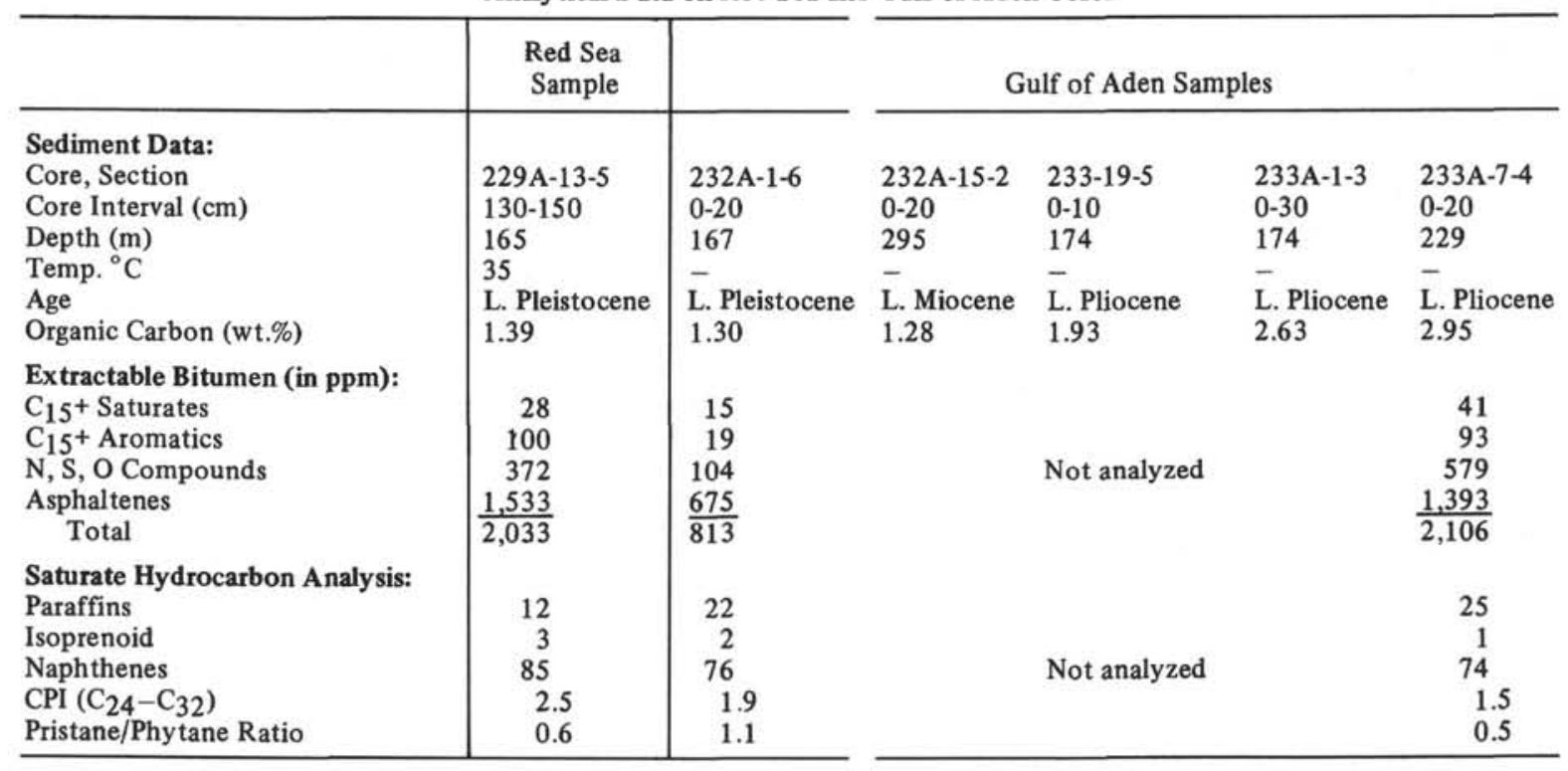

biogenetic in origin, with minor diagenetic alterations. The presence of gasoline range $\left(\mathrm{C}_{4}-\mathrm{C}_{7}\right)$ hydrocarbons indicates that conditions for generation of petroleum in the deeper sediments of this area are suitable providing such sediments contain organic carbon contents comparable to the cores that were analyzed, and providing temperatures in the deeper sections are sufficiently high to generate economic accumulations of oil.

This research was supported by National Science Foundation Grant GA-38048. 

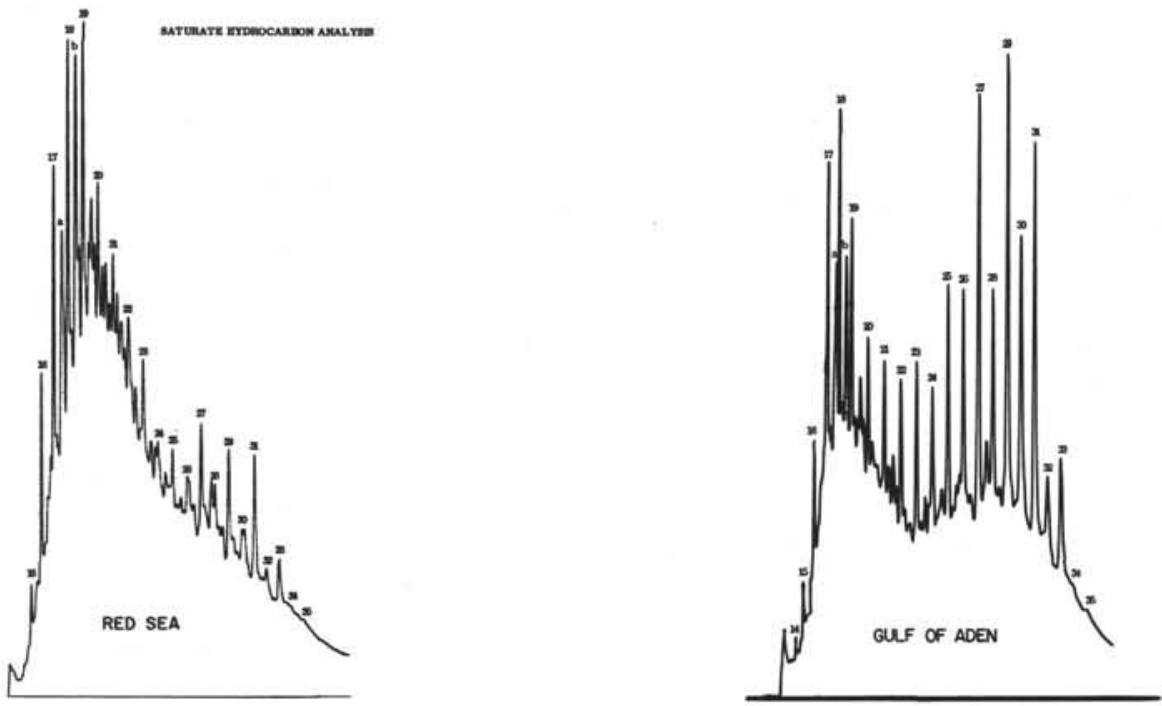

Figure 1. Gas chromatographic trace for analysis of saturated hydrocarbon fraction. 